\title{
REPRESENTATIVIDADE NEGRA FEMININA E A LEGITIMAÇÃO DE DIREITOS
}

\section{ARTIGO DE REVISÃo}

PIVA, Caroline Tito Miranda ${ }^{1}$

COSTA, Tânia Gomes Ferreira da ${ }^{2}$

PIVA, Caroline Tito Miranda. COSTA, Tânia Gomes Ferreira da. Representatividade negra feminina e a legitimação de direitos. Revista Científica Multidisciplinar Núcleo do Conhecimento. Ano 05, Ed. 05, Vol. 10, pp. 63-74. Maio de 2020. ISSN: 2448-0959, Link de acesso: https://www.nucleodoconhecimento.com.br/educacao/negra-feminina

\section{RESUMO}

Este artigo de revisão aborda a importância da representatividade negra feminina nos espaços de poder, para superação da interseccionalidade dos eixos de subordinação

${ }^{1}$ Mestranda em Ciências da Educação, pela Universidade Grendal, polo de Teixeira de Freitas-BA. Especialista em Gestão Educacional - Faculdade Batista Brasileira (FBB). Especialista em Gestão do Trabalho Pedagógico - Universidade Vale do Cricaré (UNIVC). Especialista em Psicopedagogia Clínica e Institucional - Faculdade do Sul da Bahia (FASB). Especialista em Gestão de Políticas Públicas em Gênero e Raça - Faculdade Federal da Bahia (UFBA). Graduada em Pedagogia - Universidade do Estado da Bahia (UNEB).

2 Mestranda em Ciências da Educação, pela Universidade Grendal, polo de Teixeira de Freitas-BA. Especialista em Especialista em Gestão de Políticas Públicas em Gênero e Raça- Faculdade Federal da Bahia (UFBA). Especialista em Supervisão, Coordenação, Direção e Pedagogo Escolar- Universidade Vale do Cricaré (UNIVC). Especialista em Orientação Educacional - Faculdades Integradas de Jacarepaguá (FIJ). Graduada em Pedagogia- Universidade do Estado da Bahia (UNEB). Graduada em História - Faculdade de Ciências da Bahia- (FACIBA). 
que afetam as mulheres negras, através da consciência do seu lugar de fala e da necessidade do diálogo intercultural na construção de novos conhecimentos que visem o enfrentamento ao racismo estrutural, à vulnerabilidade de gênero e a implementação de políticas públicas voltadas para melhoria da sua qualidade de vida. Tem como proposição analisar o contexto histórico e social da participação das mulheres negras nos movimentos sociais, em busca da legitimação de direitos com recorte em gênero e raça. Para tanto, revisa-se os estudos de Djamila Ribeiro (2017), Nilma Lino Gomes (2017), Vera Maria Candau (2013) e Antônio Flávio Moreira (2013) sobre a valorização da história e cultura africana e afro-brasileira para romper com o silenciamento imposto às mulheres negras, definindo o lugar de fala em espaços de decisão e oportunizando o diálogo intercultural para emancipação e instituição de direitos.

Palavras-Chave: Representatividade, feminismo, movimento sociais, direitos, lugar de fala.

\section{INTRODUÇÃO}

O estudo desenvolvido tem o objetivo de abordar algumas reflexões sobre a representatividade feminina negra, analisando os mecanismos dos movimentos sociais para legitimar os espaços de fala e de enfrentamento ao racismo, visando superar a visão estereotipada em relação as desigualdades de gênero e raça.

Debate legitimação de direitos em busca de ações concretas pela superação da invisibilidade sobre a interseccionalidade sofrida pelas mulheres negras e como seus desdobramentos se consolidaram historicamente. Tem como proposição, entender os desdobramentos do movimento negro feminista para implementação de políticas afirmativas para superação do racismo estrutural que persiste na esfera social, política e econômica do país.

A relevância em pesquisar as reivindicações pelo reconhecimento dos direitos das mulheres negras se dá, sobretudo, pela necessidade de desafiar os padrões hegemônicos e abrir espaço para o debate intercultural acerca das conjunturas 
opressoras que foram construídas e se consolidaram na construção da história brasileira.

Nessa perspectiva, a corporeidade da mulher negra é pensada como mecanismo para fortalecer os movimentos de resistência e valorização da cultura africana e afrobrasileira, contribuindo para o reconhecimento identitário e ocupação do seu lugar de fala.

O presente trabalho analisa os estudos de Djamila Ribeiro (2017), Nilma Lino Gomes (2017), Vera Maria Candau (2013) e Antônio Flávio Moreira (2013) sobre o reconhecimento da cultura africana e afro-brasileira, que incentivam a ocupação dos espaços de poder pelas mulheres negras, possibilitando um diálogo intercultural para construção de novos saberes, rompendo com a lógica colonizadora e instituindo direitos.

\section{REPRESENTATIVIDADE NEGRA FEMININA E A LEGITIMAÇÃO DE DIREITOS}

A mobilização das mulheres negras brasileiras enquanto organização estava inicialmente vinculada ao movimento feminista e negro, numa época marcada pela ditadura militar e luta pela democratização do país.

As mulheres negras buscavam um lugar de fala, para reivindicar seus direitos e dar voz às suas necessidades. Marcadas pelas forças excludentes do racismo e do sexismo, eram duplamente subalternizadas na pirâmide social, sendo silenciadas e oprimidas para que não acreditassem no poder das suas vivências e identidades como meio de emancipação. Segundo Djamila Ribeiro:

Seria urgente $o$ deslocamento do pensamento hegemônico e a ressignificação das identidades, sejam de raça, gênero, classe para que se pudesse construir novos lugares de fala com o objetivo de possibilitar voz e visibilidade a sujeitos que foram considerados implícitos dentro dessa normatização hegemônica (RIBEIRO, 2017, p. 45). 
Os movimentos negro e feminista representaram um espaço possível para reivindicação e conquista de direitos negados historicamente. A intersecção, das demandas específicas das mulheres negras, com a antirracista e antissexista, não foi uma tarefa fácil. Entretanto, o engajamento em espaços legítimos de discussão e de construção de conhecimento era vital para o enfretamento à vulnerabilidade social imposta as mulheres negras.

Partindo desse pressuposto, foi preciso focar na necessidade de especificar as demandas das mulheres negras e ocupar espaços de representatividade política. Em 1985, mulheres negras ocuparam vagas no conselho estadual e nacional dos direitos da mulher, fato que gerou pesquisas referentes as desigualdades raciais e de gênero e consequentemente políticas públicas voltadas para o combate à violência doméstica e sexual, que acomete em maior número as mulheres negras.

Dessa forma, definir o lugar de fala das mulheres negras representa reivindicar os diferentes pontos de análise, buscando entender de onde se fala para questionar as hierarquizações. Segundo Candau:

Em geral, quando se promove o diálogo intercultural se assume uma abordagem de orientação liberal e se focaliza, com frequência, as interações entre diferentes grupos socioculturais de um modo superficial, reduzindo à visibilidade de algumas expressões culturais destes grupos, sem enfrentar a temática das relações de poder que perpassam as relações interculturais, nem as matrizes profundas, mentalidades, imaginários, crenças, configuradoras de sua especificidade (CANDAU, 2013, p. 24-25).

A luta negra feminina foi marcada pela superação da invisibilidade das questões relacionadas à raça no movimento feminista e de gênero no movimento negro. Tal fato, instigou mulheres negras a refletirem sobre novas epistemologias geradas a partir do seu lugar social, valorizando concepções que convergiam as especificidades e objetivavam garantir direitos com recorte de gênero e de raça. 
Vários marcos históricos evidenciaram a conquista das mulheres negras enquanto organização sem fins lucrativos, em especial as conferências mundiais, que possibilitaram a capacitação das lideranças e recebimentos de investimentos financeiros para realização de projetos de cunho social destinados à formação e valorização das mulheres negras como: Geledes, Criola, Casa de cultura da mulher negra, Mãe Andresa e Fala preta.

O movimento feminista negro contribuiu para a promoção da igualdade de gênero e combate à discriminação contra as mulheres, pois colaborou ativamente na luta para a consolidação de direitos através da criação do programa de assistência Integral à saúde da mulher, criação dos conselhos estaduais e nacional da mulher, implementação de delegacias de polícia de defesa da mulher, garantia dos direitos reprodutivos, lançamento da plataforma política feminista para defesa dos direitos da mulher, regularização do trabalho doméstico, realização, pela fundação Carlos Chagas, de pesquisas sobre as desigualdades de gênero e raça na educação, além da implementação da lei 10.639/03 inserindo o ensino de História da África e da cultura Afro-Brasileira na educação básica. De acordo com Jurema Werneck:

Para que se compreenda a amplitude da formulação embutida na resposta político-ideológica das mulheres negras, é preciso destacar o recurso e a valorização de diferentes elementos. Entre eles estão: história, recuperando e denunciando a violência da dominação ocidental eurocêntrica e patriarcal ao longo dos tempos; tradição, compreendida como arena viva de disputas, em que atualizações e apagamentos de diferentes elementos de origem africana têm a finalidade de possibilitar novos arranjos identitários adequados aos contextos e lutas; geografia e território, afirmando, valorizando e articulando a perspectiva local e transnacional das identidades, validando seu aspecto diaspórico, que compreende a dominação racista patriarcal como luta comum de afrodescendentes nos diferentes continentes; a perspectiva de luta, elegendo o confronto à violência racista, heterossexista e eurocêntrica como central; e, por fim, a busca de autonomia e capacidade de ação 
para mudar as condições de vida das mulheres negras e de todo o grupo (WERNECK, 2009, p. 114 -115).

Dessa forma, o movimento feminista negro tem irrefutavelmente marcado a história do país, na medida em que luta contra a hegemonia eurocêntrica nas dimensões social, política, histórica e cultural, exigindo ações de reparação que visam melhorar a qualidade de vida das mulheres negras, produzindo conhecimento a partir de diferentes abordagens, na busca por legitimação de direitos, rumo a construção de uma nova sociedade.

\section{MULHERES NEGRAS E REPRESENTATIVIDADE}

Entender o que é lugar de fala e representatividade traz para o bojo das discussões de gênero e raça, o fato de que a autorização discursiva sempre foi dada ao indivíduo que pertence ao grupo dominante e ocupa espaços de poder.

Analisar como são construídas essas narrativas, significa desnaturalizar as exclusões e assumir um lugar de ativismo na construção da própria história.

O término das administrações coloniais, infelizmente não significou o fim da colonização. As hierarquias continuam existindo na sociedade atual, marcada pela colonização do ser, do saber e do poder.

Desse modo, existe um processo de exclusão dos povos subalternizados, sendo necessário pluralizar todas as vozes, através da intensa participação e resistência à desumanização imposta à essas pessoas.

Nesse contexto, o lugar de fala ocupa um papel fundamental, na medida em que representa o lugar social do indivíduo, de onde ele vem e quais são suas experiências, definindo se sua situação é de privilégio ou de opressão. Segundo Djamila Ribeiro:

O lugar social não determina uma consciência discursiva sobre esse lugar. Porém, o lugar que ocupamos socialmente nos faz ter experiências distintas e outras perspectivas. A teoria do ponto de vista 
feminista e lugar de fala nos faz refutar uma visão universal de mulher e de negritude, e outras identidades (RIBEIRO, 2017, p.71).

É preciso pluralizar todas as vozes, através da ocupação desses lugares por mulheres negras que vivenciaram situações de opressão e subalternização. A representatividade é, portanto, assumir o lugar de fala nos espaços de poder.

Quanto mais pessoas, com suas especificidades, ocupam espaços de poder, mais plurais serão as narrativas e mais justas as decisões. Sendo imprescindível questionar a formação dessa sociedade marcada pela hierarquização e que traz na sua estrutura uma visão universal.

O movimento de mulheres negras tem enfatizado a importância do lugar de fala, por sofrem com a interseccionalidade dos eixos de subordinação e acreditarem que é partindo das suas experiências e do diálogo intercultural que políticas públicas poderão ser implementadas, atendendo ao recorte de gênero e raça. De acordo com Moreira e Câmara:

Nos diferentes grupos há muitas distinções entre seus membros. No das mulheres, por exemplo, encontram-se brancas, negras, casadas, solteiras, divorciadas, mães, moradoras de diferentes cidades, apreciadoras de variadas manifestações culturais, jovens, idosas. Enfim, há uma gama de aspectos identitários que as distinguem, assim como há pontos que as unem e que permitem estabelecer elos e partilhar valores e propósitos comuns (MOREIRA; CÂMARA, 2013, p.45).

A representatividade de mulheres negras nos espaços de decisão tem sido fundamental para conquista de vários direitos. Entre essas mulheres, evidencia-se o legado de brasileiras, como Leila Gonzalez (1935 - 1994), primeira mulher negra a ser membro do Conselho Nacional dos Direitos da Mulher; Tereza de Benguela, nasceu no século XVIII, foi líder do Quilombo Quariterê. A lei no 12.987 definiu o dia 25 de julho, no Brasil, como o Dia Nacional de Tereza de Benguela e da Mulher Negra; Nilma Lino Gomes (1961), pedagoga brasileira. Tornou-se a primeira mulher negra do 
Brasil a comandar uma universidade pública federal. Corroborando, os estudos de Djamila Ribeiro apontam:

Tanto Leila Gonzalez, como Linda Alcoff, Spivak, entre outras, pensam a necessidade de romper a epistemologia dominante e de fazer o debate sobre identidades pensando o modo pelo qual o poder instituído articula essas identidades de modo a oprimir e retificá-las. Pensar lugares de fala para essas pensadoras seria desestabilizar e criar fissuras e tensionamentos a fim de fazer emergir não somente contra discursos, [...] mas visam pensar outras possibilidades de existências para além das impostas pelo regime discursivo dominante (RIBEIRO, 2017, p. 91 92).

Dessa forma, a representatividade de mulheres negras contribuiu decisivamente para uma mudança de paradigmas e construção de novos saberes, pois assumindo suas narrativas a partir do seu lugar de fala, acolheram suas responsabilidades na difícil tarefa de representar todas as mulheres negras em espaços de decisão e assim certamente estão mudando o rumo da história, na medida que colaboram para garantir a luta pelos direitos fundamentais de todo cidadão.

\section{CORPOREIDADE FEMININA NEGRA COMO FORMA DE EMANCIPAÇÃO}

As iniciativas das mulheres que desafiaram os padrões hegemônicos, compreendendo que as condições de mulheres negras lhes deixavam em uma posição social distinta em uma sociedade centrada nos mecanismos do sistema patriarcal, exigiam um debate acerca das conjunturas opressoras e pela conquista de cidadania plena.

As desigualdades que se refletem em várias dimensões da sociedade, como a violência racial e de gênero, se consolidaram sobre a população negra no processo histórico do pais, passando a ser estudadas de forma mais aprofundada através do movimento negro feminista. 
As mulheres negras se organizaram para reivindicar igualdade de direitos e de oportunidades. Sendo negras e mulheres, buscaram se capacitar para não mais aceitarem de forma normal a subordinação e o racismo estrutural que se consolidaram nas dimensões cultural, econômica e política do país, buscando cada vez mais reivindicar seu lugar de fala, dentro desse cenário.

Os movimentos sociais e culturais fortalecidos pela conquista de políticas públicas trazem uma afirmação positiva, incentivando a resistência ao preconceito e à discriminação. A valorização da cultura negra passa a ser debatida e questionada, no cotidiano de comunidades quilombolas e irmandades predominantemente negras, contribuindo para a formação indenitária de seus membros.

O corpo negro passa a ser percebido com outra perspectiva, como um suporte para fortalecer sua identidade. A linguagem corporal, suas formas de saudações, ritmos musicais, religiosidade, valores culturais e culinária passam a ter visibilidade social e contribuem para que população negra assuma seu lugar de pertencimento. Segundo Gomes:

No Brasil, corpo negro, ganha visibilidade social na tensão entre adaptarse, revoltar-se ou superar o pensamento racista que o toma como erótico, exótico e violento. Essa superação se dá mediante a publicação da questão racial como um direito, via práticas, projetos, ações políticas, cobrança do Estado e do mundo privado da presença da população negra na mídia, nos cursos superiores, na política, nos lugares de poder e decisão, na moda, na arte, entre outros. A denúncia do racismo, a sua inserção como um crime inafiançável e imprescritível sujeito à pena de reclusão garantida na Constituição de 1988, a presença dos negros e negras na mídia, no mercado de trabalho e nas universidades fazem parte desse cenário de lutas (GOMES, 2017, p.94).

Nesse contexto, as instituições de ensino sendo responsáveis por organizar, transmitir e socializar conhecimentos e valores culturais, ocupam um lugar privilegiado de troca culturais e de experiências vividas por diferentes indivíduos, oportunizando o debate 
de enfrentamento ao racismo e de superação da visão estereotipada da cultura africana e afro-brasileira.

As instituições de educação se apresentam como um dos meios de socialização de diálogos reguladores sobre o corpo negro. O movimento negro, em especial de mulheres negras, tem buscado a superação desse conceito dominante, incentivando intervenções artísticas, poética e política, através da juventude negra. De acordo com Gomes:

A educação pode desenvolver uma pedagogia corporal que que destaque a riqueza da cultura negra inscrita no corpo, nas técnicas corporais, nos estilos de penteados e nas vestimentas, as quais também são transmitidas oralmente. São aprendizados da infância e da adolescência. O corpo negro pode ser tomado como símbolo de beleza, e não inferioridade. Ele pode ser visto como corpo guerreiro, belo atuante presente na história do negro da diáspora, e não como corpo de escravo, servil, doente e acorrentado (GOMES, 2003, p.6).

A luta da comunidade negra, no Brasil, pela emancipação do seu corpo, atravessa o viés regulador de uma sociedade capitalista, racista e machista. Essa regulação acontece em harmonia com a ideologia da raça biológica, mascarada no mito da democracia racial. Dá um novo significado ao sistema de regulação conservador é um papel político do movimento negro, que através de ações afirmativas, precisa buscar alternativas para ressignificar e recodificar as ações políticas que fortaleçam a construção identitária do povo negro. A este respeito GOMES diz que:

É possível observar que jovens e negros que participam de processos de ações afirmativas tendem a estabelecer relação diferente com a sua corporeidade. Há, então, a produção de outro saber sobre o corpo, que passa a ser compartilhado com pessoas de outros segmentos étnicosraciais e a ser notado pelas famílias. De certa forma, há uma ocupação do corpo negro nos espaços que antes não estavam acostumados a lidar com tal corporeidade (GOMES, 2017, p.115). 
Nessa perspectiva, o debate sobre corporeidade negra se faz fundamental para reeducar os negros nesse processo contemporâneo marcado por tensão regulaçãoemancipação social, buscar redefinir as ações desenvolvidas nas instituições de ensino que recebe todos os corpos, cada um com suas peculiaridades, a delinear outros contornos.

É crucial abrir espaço para debater as leituras acerca da beleza da mulher negra, qual é o seu papel no contexto sociocultural brasileiro e como a sua figura é projetada nos espaços já ocupados.

Perceber o mundo é aprender e aprender o mundo com o corpo, é perceber o corpo. Isto implica na integração de modelos sociais. A descoberta do corpo é a formação da imagem do corpo passam por situações sociais. É na interação com outras pessoas do entorno social que os modelos são internalizados, isto é, nas vivencias e experiências, que são intransferíveis e subjetivas (FREITAS, 2008. p.323).

Portanto, ressignificar e construir representações positivas da mulher negra, sua história, sua cultura, sua corporeidade e sua estética, são ações fundamentais para correção das desigualdades construídas no processo histórico do país, oportunizando reparação de oportunidades e de direitos.

\section{CONCLUSÃO}

Compreender a importância da representatividade feminina negra, nos espaços de decisão, é fundamental para o entendimento do contexto histórico e social que envolvem a luta negra feminina e quais os desafios encontrados para a legitimação dos direitos com recorte em gênero e raça.

Na contemporaneidade, Djamila Ribeiro (2017) tem enfatizado o conceito de lugar de fala, como sendo fundamental para romper com os vários eixos de subordinação impostos às mulheres negras. Para a autora, através da consciência do seu lugar de fala, as mulheres negras legitimam a ocupação de espaços de poder, visando uma 
troca intercultural na construção de novos conhecimentos, que atendam suas especificidades e vivencias, retificando seus direitos.

Moreira e Candau (2013) abordam a necessidade de reconhecimento do dialogo intercultural, na medida em que as diferenças podem ser vistas como oportunidades para construção de um projeto comum de sociedade, que atenda as diferentes identidades socioculturais.

Dessa forma, a luta das mulheres negras para ocupar espaços de poder e assumir suas particularidades, a partir do seu lugar de fala, representou um grande avanço na conquista dos direitos feministas negros, como a criação dos conselhos da condição feminina, das delegacias especializadas ao atendimento à mulher, regularização do trabalho doméstico, direitos reprodutivos, além da criação e financiamento de vários projetos voltados para a formação e cuidado da mulher negra.

Corroborando, Nilma Lino Gomes (2017) elucida que o corpo negro ganha um outro olhar quando passa a ser considerado um suporte para reforçar sua identidade. A linguagem corporal valorizada como símbolo de beleza e de representatividade contribui para a emancipação das mulheres negras e a busca por seu lugar de pertencimento.

Assim, desconstruir os processos de subalternização enraizados pela colonização, exige das mulheres negras uma luta interseccional contra a opressão e o silenciamento imposto até a contemporaneidade, de forma que reverberem políticas e ações em prol da qualidade de vida e do reconhecimento do legado dessas grandes mulheres.

\section{REFERÊNCIAS}

CANDAU, Vera Maria. Multiculturalismo e educação: desafios para a prática pedagógica. In: MOREIRA, Antônio Flávio Barbosa; CANDAU, Vera Maria (orgs.). Multiculturalismo: diferenças culturais e práticas pedagógicas. 10.ed. Petrópolis, RJ: Vozes, 2013. p. 13-37. 
FREITAS, Neli Klix. Esquema corporal, imagem visual e representação do próprio corpo: questões teórico-conceituais. Revista Ciências \& Cognição,v. 13, n. 3, 2008.p. 318-324. Disponível em: <http://www.cienciasecognicao.org/pdf/v13_3/m318297.pdf> . Acesso em 28 abr. 2020.

GOMES, Nilma Lino. O movimento negro educador: saberes construídos nas lutas por emancipação. Petrópolis, RJ: Vozes, 2017.

, Nilma Lino. Cultura negra em educação. Revista Brasileira de Educação, $n$. 23, Rio de janeiro, 2003. p.75-85. Disponível em: <https://doi.org/10.1590/S141324782003000200006>. Acesso em: 02 maio 2020.

MOREIRA, Antônio Flávio; CÂMARA, Michelle Januário. Reflexões sobre currículo e identidade: implicações para a prática pedagógica. In: MOREIRA, Antônio Flávio Barbosa; CANDAU, Vera Maria (Orgs.). Multiculturalismo: diferenças culturais e práticas pedagógicas. 10.ed. Petrópolis, RJ: Vozes, 2013. p. 38-66.

RIBEIRO, Djamila. O que é lugar de fala?. Belo Horizonte, MG: Letramento, 2017.

WERNECK, Jurema. Mulheres negras brasileiras e os resultados de Durban. In: PAULA, Marilene de; HERINGER, Rosana (orgs.). Caminhos convergentes: Estado e Sociedade na superação das desigualdades raciais no Brasil. Rio de Janeiro: Fundação Heinrich Boll e ActionAid, 2009. p. 111-136.

Enviado: Maio, 2020.

Aprovado: Maio, 2020. 